\title{
Theta bursts in the olfactory nerve paired with $\beta$-adrenoceptor activation induce calcium elevation in mitral cells: A mechanism for odor preference learning in the neonate rat
}

\author{
Qi Yuan ${ }^{1}$ \\ Division of Biomedical Sciences, Faculty of Medicine, Memorial University of Newfoundland, St. John's, Newfoundland and
Labrador A1B 3V6, Canada; Department of Neuroscience, University of California at San Diego, La Jolla, California 92093, USA
}

Odor preference learning in the neonate rat follows pairing of odor input and noradrenergic activation of $\beta$-adrenoceptors. Odor learning is hypothesized to be supported by enhanced mitral cell activation. Here a mechanism for enhanced mitral cell signaling is described. Theta bursts in the olfactory nerve (ON) produce long-term potentiation (LTP) of glomerular excitatory postsynaptic potentials (EPSPs) and of excitatory postsynaptic currents (EPSCs) in the periglomerular (PG) and external tufted (ET) cells. Theta bursts paired with $\beta$-adrenoceptor activation significantly elevate mitral cell $(\mathrm{MC})$ calcium. Juxtaglomerular inhibitory network depression by $\beta$-adrenoceptor activation appears to increase calcium in MCs in response to theta burst stimulation.

Early odor preference learning provides us with a model in which the necessary and sufficient inputs for learning can be localized to a relatively simple cortical structure, the olfactory bulb (Sullivan et al. 2000). The critical changes for this natural form of learning occur in the olfactory bulb network (Coopersmith and Leon 1986, 1987, 1995; Wilson et al. 1987; Woo et al. 1987; Wilson and Leon 1988; Wilson and Leon 1991; Guthrie et al. 1993; Johnson et al. 1995; Yuan et al. 2002). Odor preference learning is induced by the pairing of odor with activation of the locus coeruleus noradrenergic system, a component of our arousal circuitry (Harley 1987; Berridge and Waterhouse 2003; Berridge 2008), which is critically involved in other forms of memory (Harley 1987; Berridge and Waterhouse 2003) and compromised in diseases of memory, such as Alzheimer's (Palmer and DeKosky 1993; Weinshenker 2008). The unconditioned stimulus for early odor preference learning is mediated by $\beta$-adrenoceptor activation in the olfactory bulb (Sullivan et al. 1991, 1992; Wilson and Sullivan 1991, 1994; Wilson et al. 1994; Harley et al. 2006). $\beta$-Adrenoceptor agonists and antagonists infused in the olfactory bulb can induce or block learning, respectively (Sullivan et al. 1989, 2000).

Despite the fact that the behavioral model for early odor preference learning has been established for decades (Sullivan et al. 1988, 1989), and despite the fact that the olfactory bulb circuit contains synapses that are essential for the formation of a localizable long-term memory that is easily indexed in behavior (Coopersmith and Leon 1986; Wilson et al. 1987; Woo et al. 1987; Wilson and Leon 1988; Woo and Leon 1991; Johnson et al. 1995; McLean et al. 1999; Yuan et al. 2002), the circuitry and the synapses in the olfactory bulb that mediate learning are not well understood. Long-term potentiation (LTP), the putative synaptic model for associative learning in other brain regions (Bliss and Lomo 1973; Brown et al. 1988; Barnes 1995; Malenka 1994), has not been demonstrated compellingly in the rat olfactory bulb. The lack of evidence for a synaptic locus and a mechanism to support odor preference learning is partly due to the dissociation of the

\footnotetext{
'Corresponding author.
}

E-mail qi.yuan@med.mun.ca; fax (709) 777-7010.

Article is online at http://www.learnmem.org/cgi/doi/10.1101/lm.1569309. neural changes previously observed following early odor learning (seen at the glomerular input level) (Coopersmith and Leon 1986; Wilson et al. 1987; Woo et al. 1987; Wilson and Leon 1988; Woo and Leon 1991; Johnson et al. 1995; Yuan et al. 2002) and the innervation pattern of noradrenergic fibers in the olfactory bulb (seen mostly in the deep layers of the olfactory bulb, but sparse in the glomerular layer) (McLean et al. 1989; McLean and Shipley 1991).

McLean and colleagues have proposed, based on physiological and anatomical evidence, that early odor preference learning leads to a long-term facilitation of the olfactory nerve $(\mathrm{ON})$ inputs to mitral cells (MCs, the main output cell of the olfactory bulb) (McLean et al. 1999; Yuan et al. 2003b; McLean and Harley 2004). In the present study, odor input is mimicked in vitro by theta burst stimulation (TBS) of the ON, and the modulation of glomerular and $\mathrm{MC}$ responses to theta bursts alone and in conjunction with bath application of the $\beta$-adrenoceptor agonist, isoproterenol, is assessed. The results support the McLean glomerular/MC hypothesis of early odor preference learning.

In the first set of experiments (Fig. 1A-D), the effects of theta burst $\mathrm{ON}$ input on the field glomerular excitatory postsynaptic potential (EPSP) were tested. The $\mathrm{ON}$ was stimulated by a single test stimulus $(20-100 \mu \mathrm{A})$ every $20 \mathrm{sec}$ in horizontal olfactory bulb slices from postnatal 6-14-d-old Sprague-Dawley rats (Fig. 1A). TBS (10 bursts of high frequency stimulation at $5 \mathrm{~Hz}$, each burst containing five pulses at $100 \mathrm{~Hz}$, same stimulation intensity as test stimuli) that mimics the sniffing cycles in the ON (Kepecs et al. 2006) was given after a baseline was taken. All the experiments were done in aCSF containing (in millimolars) $119 \mathrm{NaCl}, 2.5 \mathrm{KCl}$, $1.3 \mathrm{MgSO}_{4}, 1 \mathrm{NaH}_{2} \mathrm{PO}_{4}, 26.2 \mathrm{NaHCO}_{3}, 22 \mathrm{mM}$ glucose, and 2.5 $\mathrm{CaCl}_{2}$, equilibrated with $95 \% \mathrm{O}_{2} / 5 \% \mathrm{CO}_{2}$. Field recording pipettes were filled with aCSF. All recordings were acquired at $30^{\circ} \mathrm{C}-32^{\circ} \mathrm{C}$. Data are presented as mean \pm SEM. Student's $t$-test was used to determine statistical significance.

There was on average a $14.5 \pm 2.5 \%$ increase in the field EPSP peak amplitude at $30 \mathrm{~min}$ post TBS induction $(N=34, t=5.82, P<$ 0.001 , Fig. 1B). Bath application of D-APV $(50 \mu \mathrm{M})$, an NMDAR antagonist, did not eliminate TBS potentiation; the EPSP peak is $115.6 \pm 5.4 \%$ of baseline, 30 min post-induction $(N=5, t=2.90$, 


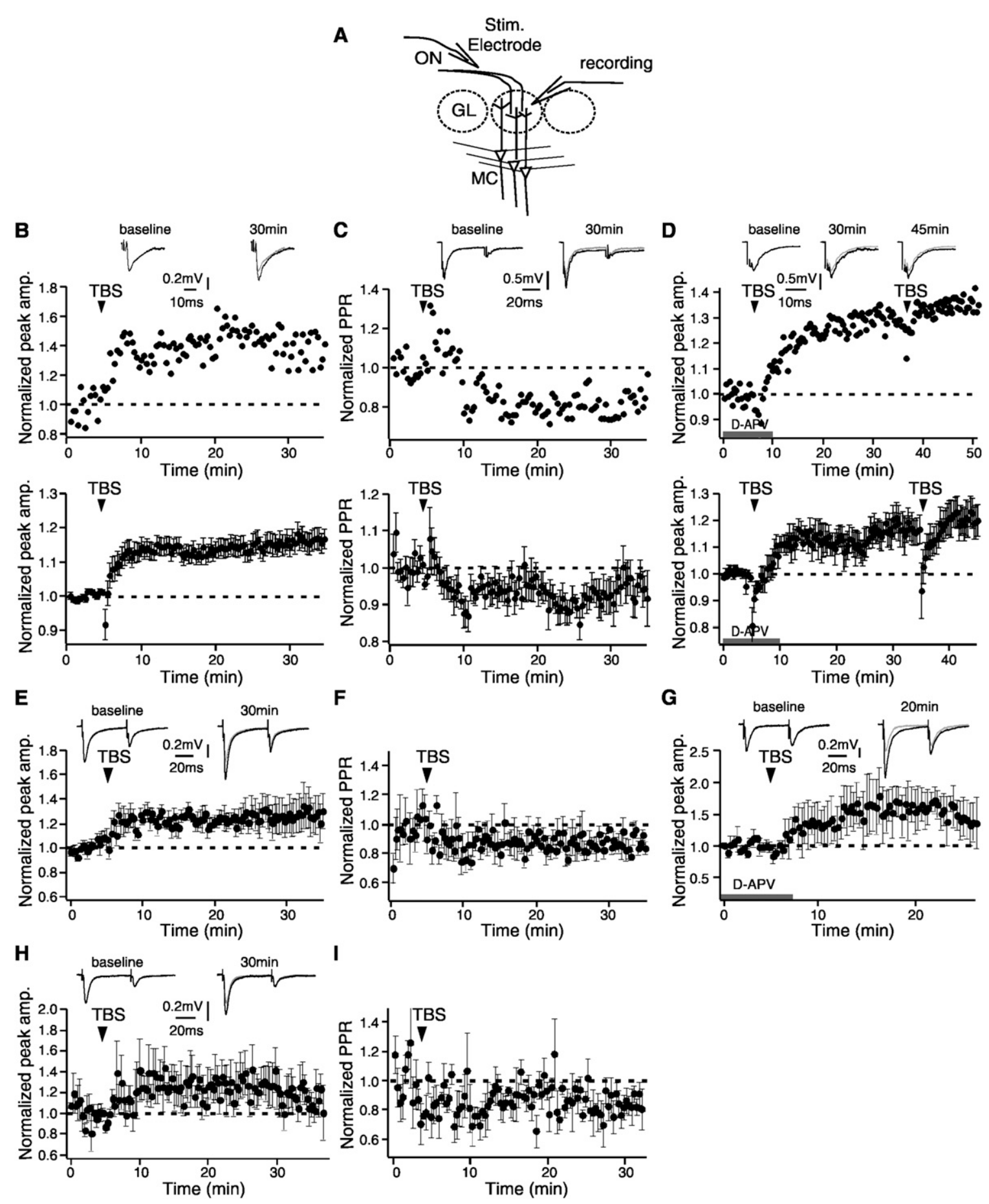

Figure 1. Theta LTP can be induced in the olfactory bulb first synapses. (A) Stimulation and recording configuration. A bipolar stimulation pipette was placed on a bundle of $\mathrm{ON}$ fibers that innervated the recorded glomerulus. ON, olfactory nerve; GL, glomerular layer; $M C$, mitral cell. (B-D) LTP of glomerular field EPSPs induced by ON theta burst stimulation (TBS). (B) Time course of glomerular field EPSPs (upper: single example; lower: average traces from $N=34$ recordings). Note field EPSP was potentiated following TBS. (C) Paired-pulse ratio (PPR, $N=7$ ) of ON field EPSPs (interval 50 msec) was depressed following TBS. (D) LTP of glomerular field EPSPs was D-APV independent $(N=5)$. $(E-G)$ TBS of ON induced LTP in postsynaptic external tufted (ET) cells. (E) Time course of EPSCs recorded from ET cells $(N=6)$. ( $F)$ PPR of EPSCs $(N=4)$. (G) LTP of ET cell EPSCs are D-APV independent $(N=3)$. $(H, I)$ TBS of ON induced potentiation of periglomerular (PG) cell EPSCs. $(H)$ Time course of EPSCS $(N=8)$. (I) PPR of EPSCS $(N=4)$.

$P=0.022$, Fig. 1D). This result suggests that plasticity occurs at the first step of odor processing (Ennis et al. 1998; Mutoh et al. 2005; Tyler et al. 2007; Dong et al. 2008; Jones et al. 2008). Hence, the synapses between the $\mathrm{ON}$ and its postsynaptic neurons are potential targets for learning-dependent plasticity as suggested by the long-lasting metabolic and anatomical changes observed at the olfactory bulb glomerular level following early odor preference training (Coopersmith and Leon 1986; Wilson et al. 1987; Woo et al. 1987; Wilson and Leon 1988; Woo and Leon 1991; Johnson et al. 1995; Yuan et al. 2002). Paired stimuli given to the ON using 
a 50-msec interval were used to test presynaptic changes to TBS. Paired-pulse ratios, an indicator of changes in presynaptic release (Murphy et al. 2004), decreased following TBS $(91.5 \pm 2.8 \%$ of control, $N=7, t=3.05, P=0.011$, Fig. 1C). The decrease in pairedpulse ratio suggests TBS potentiation is presynaptically mediated. The glomerular potentiation seen here is consistent with a recent adult mouse model showing an increase in odor-specific glomeruli and olfactory sensory neurons following odor learning (Jones et al. 2008).

In the second set of experiments, glomerular excitatory postsynaptic currents (EPSCs) in postsynaptic juxtaglomerular (JG) cells were recorded in voltage-clamp mode (membrane potential held at $-60 \mathrm{mV}$ ). The effects of TBS on JG cell EPSCs were tested. Patch pipettes were filled with an internal solution containing (in millimolars) 114 K-gluconate, $17.5 \mathrm{KCl}, 4 \mathrm{NaCl}, 4 \mathrm{MgCl}_{2}, 10$ HEPES, 0.2 EGTA, $3 \mathrm{Mg}_{2} \mathrm{ATP}$, and $0.3 \mathrm{Na}_{2} \mathrm{GTP}$. There are two main populations of JG cells in the glomeruli, periglomerular (PG) cells, and external tufted (ET) cells. PG cells are inhibitory on MCs (Murphy et al. 2005), while ET cells are excitatory neurons, which receive monosynaptic ON input and then excite PG interneurons (Hayar et al. 2004). PG cells form two functionally distinct populations: $\sim 30 \%$ are driven by monosynaptic ON input, while the remaining population receive their input mainly through ET cells (ON-ET-PG circuit) (Shao et al. 2009). These JG cells form a glomerular inhibitory network in which inhibitory PG cells (activated by either ON input or ET cells) provide both feed-forward and feedback inhibition to MCs of the olfactory bulb through dendrodendritic synapses (Hayar et al. 2004; Murphy et al. 2005). ET cells can be distinguished from PG cells by their morphology, location, and characteristic spontaneous rhythmic spike bursting pattern recorded extracellularly before switching to whole-cell voltage-clamp mode (Hayar et al. 2004; Dong et al. 2007). ET cells were significantly potentiated by TBS while the TBS effect on PG cells was more moderate and more variable (ET: $124.1 \pm 11.4 \%$ of control at $30 \mathrm{~min}$ post-induction, $N=6, t=2.12, P=0.043$, Fig. $1 \mathrm{E}$; PG: $115.7 \pm 15.5 \%, N=8, t=1.01, P=0.172$, Fig. $1 \mathrm{H})$. It should be noted that there is a stronger dialysis effect in small cells, such as the PG cells, which is suggested to account for the weaker and more variable potentiation in this subgroup. Three PG cells showed compelling potentiation (164 $\pm 13.5 \%$ of control at 30 min postinduction, $t=4.73, P=0.021)$. The paired-pulse ratio of the EPSCs was reduced following TBS induction (ET: $81.6 \pm 4.6 \%$ of control, $N=4, t=4.01, P=0.014$, Fig. 1F; PG: $80.1 \pm 10.5 \%, t=1.90, P=$ 0.070 , Fig. $1 \mathrm{I})$, consistent with a presynaptic expression mechanism. Furthermore, ET cell LTP was NMDA-receptor independent when tested with APV $(161.9 \pm 23.3 \%$ of control, 15 min postinduction, $N=3, t=2.66, P=0.028$, Fig. $1 \mathrm{G})$.

The role of theta LTP in learning is of particular interest because this pattern of activation is likely to occur in the ON. Since theta is the frequency associated with sniffing in the olfactory bulb (Kepecs et al. 2006), it is straightforward to hypothesize that it has a role in the learning of odor associations. Yet odor preference learning does not occur with odor exposure per se. An interaction between a theta paced odor input and the arousal modulator, norepinephrine (NE), is critical.

In the third set of experiments, calcium imaging was used to examine the network of MC responses in each slice. Conventionally, it has been assumed that the glomerular field EPSP mostly
A

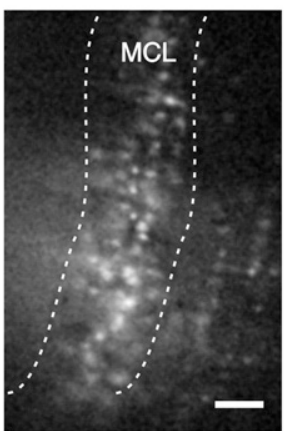

B
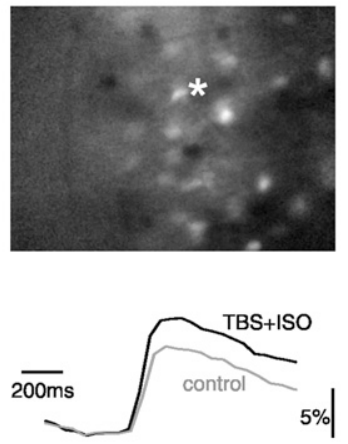

C

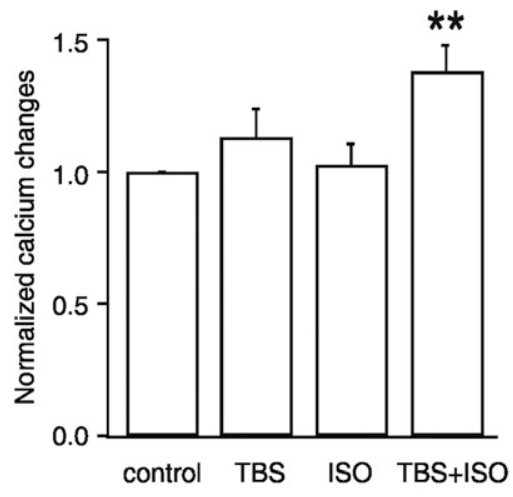

C1

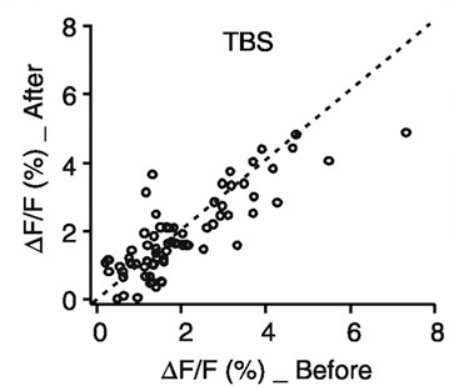

C2

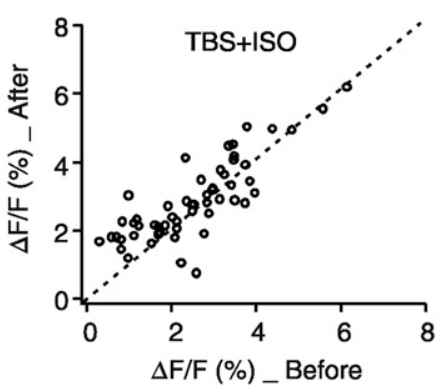

C3

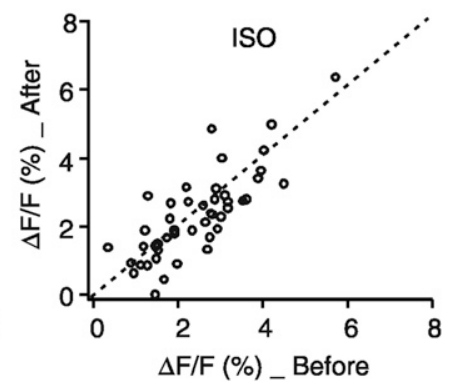

Figure 2. Pairing of TBS and isoproterenol (ISO) increased $\mathrm{MC}$ calcium responses. (A) $\triangle \mathrm{F} / \mathrm{F}$ calcium image (20× objective) of a slice stained with a calcium indicator dye, Oregon Green BAPTA-1 AM. The MC layer is labeled by white dashed lines. Scale bar, $50 \mu \mathrm{m}$. (B) An example of $\Delta \mathrm{F} / \mathrm{F}$ calcium imaging showing enhanced calcium responses following TBS+ISO in one MC (white asterisk). Lower traces are calcium transients recorded from the soma of the MC. (C) Averaged calcium transient changes in MCs following TBS, ISO, and TBS+ISO (normalized to control), measured at 30 min postmanipulations. ${ }^{* *} P<0.01$. (C1) Single-cell calcium transient changes before and after TBS. Dashed black line indicates no change. Cells above the dashed line show increased calcium responses, whereas those below the dashed line show decreased calcium responses. (C2) MC calcium responses to paired TBS and ISO. Note that the majority of MCs showed increased calcium responses following TBS+ISO. (C3) MC calcium responses to ISO only. 
reflects MC activity (Mori 1987; Shipley et al. 1996). But recent studies demonstrate the contribution of other cell types to the glomerular field EPSP such as the JG cells (ET and PG cells) (Karnup et al. 2006) monitored here. Therefore, the glomerular field EPSP is not a simple summation of synchronized MC activity. Moreover, synaptic activities at MC dendritic tufts in glomeruli may not propagate efficiently enough to the soma to change MC spiking rate due to the significant length of MC apical dendrites (Karnup et al. 2006). Therefore, this set of experiments used direct monitoring of MC activity through calcium imaging to characterize activity-dependent changes in the olfactory bulb output map. Calcium imaging permits the examination of a large population of neurons with single-cell resolution (Egger 2007).

A calcium indicator dye, Oregon Green BAPTA-1, was pressureinjected into the MC layer to stain populations of MCs (Fig. 2A,B). Calcium transients were imaged at $494 \mathrm{~nm}$ excitation $(15-20 \mathrm{~Hz}$, $2 \times 2$ binning). Regions of interest ( $\sim 20 \mu \mathrm{m}$ diameter) centered over MC somata were used for kinetic analysis. By selecting 8-12 cells per slice (including both strongly and weakly activated cells), and measuring single $\mathrm{MC}$ somatic calcium transients $(\Delta \mathrm{F} / \mathrm{F}$, average over six to eight trials, background subtracted from an immediate adjacent area next to the somata), changes were observed in the MC responses to ON stimulation (40-100 $\mu \mathrm{A}) 30 \mathrm{~min}$ following TBS (the same time point at which the magnitude of theta LTP in the glomerular layer was measured). The overall MC calcium responses to $\mathrm{ON}$ stimulation were not significantly affected by TBS $(113.0 \pm 10.5 \%$ of control, $N=74$ cells from nine slices, $t=1.24, P=0.220$, Fig. 2 panel C1). The olfactory bulb network is, as noted, functionally complex with both feed-forward and feedback inhibition modifying the MC responses to ON/odor stimulation (Murphy et al. 2005). Given the increase in coupling to inhibitory interneurons seen in the second set of experiments, it may be that enhanced feed-forward inhibition from the inhibitory JG network prevented an increase in MC responding. However, it should be noted that increases in MC responses related to TBS could be masked due to the limitation of the in vitro methodology (e.g., selected cells may include those projecting to glomeruli further away from the stimulation site and those deeper in the tissue which have weaker signal-to-noise ratios). However, as subsequent experiments, described below, reveal significant MC calcium responses with the same in vitro methodology, it is likely that the response to TBS alone is relatively minor.

Since TBS itself was not sufficient to produce significant MC calcium responses, the combined effect of TBS and the $\beta$-adrenoceptor agonist, isoproterenol, were examined. Isoproterenol was applied to the bath solution 5-10 min before the TBS and washed out after the TBS induction. The pairing of TBS and isoproterenol $(10 \mu \mathrm{M})$ increased MC calcium responses in most of the cells measured $(137.0 \pm 11.0 \%$ of control, $N=55$ from five slices, $t=3.27, P<0.001$, Fig. 2 panel C2). Five to ten min application of isoproterenol alone to the bath solution did not alter the MC responses observed $30 \mathrm{~min}$ after isoproterenol washout $(102.5 \pm 8.8 \%$ of control, $N=47$ from four slices, $t=0.28, P=0.781$, Fig. 2 panel C3). Thus, the potentiated MC calcium response was only seen with paired isoproterenol and TBS. As a caveat it should be noted that MCs fire action potentials spontaneously in vivo at $\sim 3 \mathrm{~Hz}$ (Cang and Isaacson 2003) and in vitro at $\sim 15$ $\mathrm{Hz}$ (up to $75 \mathrm{~Hz}$ ) (Griff et al. 2008). A change in $\Delta \mathrm{F} / \mathrm{F}$ calcium response reflects a change in the ratio of the evoked response over the baseline spontaneous response. Changes in MC spontaneous firing, therefore, can affect the $\Delta \mathrm{F} / \mathrm{F}$ calcium signal measured from the MC. However, if pairing TBS with isoproterenol increased spontaneous firing, the increase in the evoked firing rate of MCs had to occur to a greater degree.

This result, that only the pairing of TBS with isoproterenol enhanced MC calcium responses, correlates with the behavioral studies (Langdon et al. 1997; Sullivan and Leon 1987; Sullivan et al. 2000) showing that only the pairing of an odor and isoproterenol produces associative learning, while either odor alone or isoproterenol alone does not lead to associative learning. It supports the view that at the level of physiological mechanism, classical conditioning is the interaction of arousal modulation and theta modulation while either alone does not create the necessary associative conditions. Consistent with previous work showing enhanced CREB phosphorylation in MCs following learning (McLean et al. 1999; Yuan et al. 2000, 2003a), the present calcium imaging results support the hypothesis that odor learning results in increased firing in odor encoding MCs. Increased firing in MCs is also consistent with recent work by Gire and Schoppa showing that the pairing of NE with TBS induces an enhancement of MC long-lasting depolarization and gamma frequency oscillation (Gire and Schoppa 2008). Interestingly, MC firing is mainly suppressed to a familiar odor in neonatal rats (Wilson et al. 1985). TBS potentiation of the inhibitory JG circuitry may contribute to the odor habituation observed behaviorally.

In the fourth set of experiments, the effects of isoproterenol on JG cell activity were examined. Previous research using slice physiology to identify a synaptic site of NE action was constrained by the known distribution of noradrenergic input to the olfactory bulb. Noradrenergic fibers project heavily to the subglomerular layers; they terminate densely in the internal plexiform and the granule cell (GC) layers, and moderately in the external plexiform and the MC layers (McLean et al. 1989). Based on this anatomical evidence, it was assumed that either GCs or MCs were the potential targets for $\beta$-adrenoceptor action. However, the Ennis group showed that the $\beta$-adrenoceptor agonist isoproterenol has no direct effect on MC excitability in acute rat olfactory bulb slices (Hayar et al. 2001). Although isoproterenol caused an inward current in MCs in voltage-clamp mode, this inward current was blocked by synaptic transmission blockers, suggesting an indirect effect of isoproterenol, possibly through interneurons. NE could disinhibit MCs through suppressing GC activity as reported in the turtle and dissociated rat olfactory bulb cultures (Jahr and Nicoll

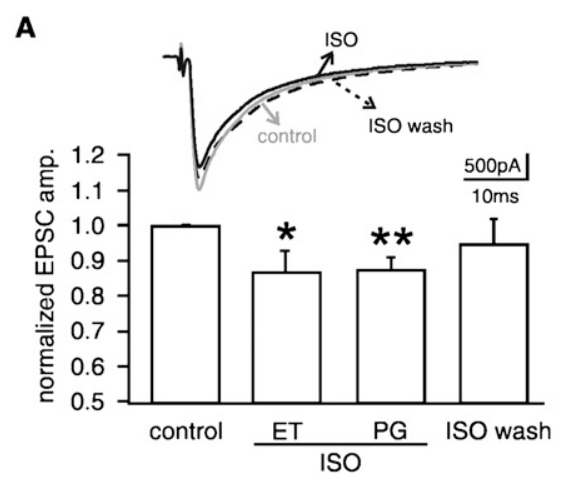

Figure 3. The effects of ISO on JG cells (PG+ET cells). (A) ISO $(10 \mu \mathrm{M})$ application suppressed EPSCs of ET cells $(N=6)$ and PG cells $(N=7)$, which was reversed following ISO washout $(N=3) .{ }^{*} P<0.05,{ }^{* *} P<$ 0.01. (B) ISO application suppressed ON-evoked calcium transients in JG cells $(N=7$ slices). The ISO effect was reversed 30 min after washout $(N=3) . N=2$ experiments were recorded from slices of a cut that was made between the glomerular layer and the MCs layer. ${ }^{* *} P<0.01$ 
1982; Trombley and Shepherd 1992; Trombley 1994). However, this effect was attributed to an $\alpha 2$-, but not $\beta$-adrenoceptor, mediated presynaptic inhibition of GC and/or MC dendrites (Trombley 1992, 1994; Trombley and Shepherd 1992). Since isoproterenol here altered MC calcium responses to ON theta burst input, it was possible that JG cells were potential targets for NE action. Studies using immunocytochemistry (Yuan et al. 2003b) and receptor autoradiography (Woo and Leon 1995) show that $\beta$-adrenoceptors are expressed in JG cells (Woo and Leon 1995; Yuan et al. 2003b), as well as in MCs (Yuan et al. 2003b) and GCs (Woo and Leon 1995).

With the application of isoproterenol the JG cell EPSCs to ON stimulation were suppressed (ET: $86.6 \pm 6.0 \%$ of control, $N=6$, $t=2.25, P=0.037$, Fig. $3 \mathrm{~A}$; PG: $87.3 \pm 3.6 \%, t=3.55, P=0.006$, Fig. $3 \mathrm{~A})$. Isoproterenol was applied for $5 \mathrm{~min}$ in the bath solution and then washed out. The effect of isoproterenol was reversed after washout $(94.8 \pm 6.7 \%, N=3, t=0.78, P=0.259$, Fig. 3A). Similar results were found with calcium imaging using the averaged cell calcium transients from 8-20 cells per slice (Fig. 3B). The averaged response from each slice was counted as one experiment. JG cell calcium transients were suppressed in the presence of isoproterenol $(83.7 \pm 3.0 \%$ of control, $N=7, t=5.40, P=0.002$, Fig. $3 \mathrm{~B})$. The effect of isoproterenol was reversed $30 \mathrm{~min}$ following washout $(100.6 \pm 1.8 \%$ of control, $N=3, t=0.36, P=0.754)$. In two experiments, recordings were made from slices that had a cut between the MC and the glomerular layer to isolate the potential secondary effect from MCs onto JG cells. In this case, isoproterenol still suppressed JG cell calcium transients (Fig. 3B, dashed circles).

Given the results of both whole-cell recording and calcium imaging, it was reasonable to hypothesize that isoproterenol would decrease JG cell activity, reducing GABA release onto MCs and causing MC disinhibition. Indeed, it has been shown NE application caused a reduction of inhibitory postsynaptic currents (IPSCs) in MCs (Gire and Schoppa 2008). Taken together these findings support the enhanced MC excitation model for early odor preference learning. While the present experiments were conducted with the $\beta_{1 / 2}$ agonist, isoproterenol, associative odor preference learning depends on $\beta_{1}$, not $\beta_{2}$, receptors (Harley et al. 2006). $\beta_{1}$ adrenoceptors are also expressed in JG cells (Yuan et al. $2003 \mathrm{~b})$. The role of specific $\beta$-adrenoceptor subtypes in mediating MC disinhibition will be tested in the future studies.

The present results argue that potentiation of MC calcium responses occurs only when theta frequency activity is paired with $\beta$-adrenoceptor activation. They also suggest that one critical role of $\mathrm{NE}$ activation via $\beta$-adrenoceptors in the olfactory bulb is to suppress the inhibitory JG network, subsequently transiently disinhibiting MCs and providing the conditions for strengthening $\mathrm{ON}-\mathrm{MC}$ connections in selected glomeruli. This mechanism likely operates in concert with changes promoted by patterned cAMP waves in MCs (Cui et al. 2007).

\section{Acknowledgments}

The author wishes to thank Dr. Jeffry Isaacson at UCSD for his generous support. This work was done in his laboratory at UCSD, supported by NIH grant R01 DC04682. Special thanks to Professors Carolyn Harley and John McLean at Memorial University for their critical reading and comments.

\section{References}

Barnes CA. 1995. Involvement of LTP in memory: Are we "searching under the street light"? Neuron 15: 751-754.

Berridge CW. 2008. Noradrenergic modulation of arousal. Brain Res Brain Res Rev 58: $1-17$.

Berridge CW, Waterhouse BD. 2003. The locus coeruleus-noradrenergic system: Modulation of behavioral state and state-dependent cognitive processes. Brain Res Brain Res Rev 42: 33-84.
Bliss TV, Lomo T. 1973. Long-lasting potentiation of synaptic transmission in the dentate area of the anaesthetized rabbit following stimulation of the perforant path. J Physiol 232: 331-356.

Brown TH, Chapman PF, Kairiss EW, Keenan CL. 1988. Long-term synaptic potentiation. Science 242: 724-728.

Cang J, Isaacson JS. 2003. In vivo whole-cell recording of odor-evoked synaptic transmission in the rat olfactory bulb. J Neurosci 23: 41084116.

Coopersmith R, Leon M. 1986. Enhanced neural response by adult rats to odors experienced early in life. Brain Res 371: 400-403.

Coopersmith R, Leon M. 1987. Glycogen phosphorylase activity in the olfactory bulb of the young rat. J Comp Neurol 261: 148-154.

Coopersmith R, Leon M. 1995. Olfactory bulb glycogen metabolism: Noradrenergic modulation in the young rat. Brain Res 674: 230-237.

Cui W, Smith A, Darby-King A, Harley CW, McLean JH. 2007. A temporalspecific and transient cAMP increase characterizes odorant classical conditioning. Learn Mem 14: 126-133.

Dong HW, Hayar A, Ennis M. 2007. Activation of group I metabotropic glutamate receptors on main olfactory bulb granule cells and periglomerular cells enhances synaptic inhibition of mitral cells. J Neurosci 27: 5654-5663.

Dong HW, Nai Q, Ennis M. 2008. Activity-dependent plasticity in the strength of $\mathrm{ON}(\mathrm{ON})$ synapses in the rat main olfactory bulb (MOB). In Society for Neuroscience Abstract, Washington D.C.

Egger V. 2007. Imaging the activity of neuronal populations: When spikes don't flash and flashes don't spike. J Physiol 582: 7. doi: 10.1113/ jphysiol.2007.136036.

Ennis M, Linster C, Aroniadou-Anderjaska V, Ciombor K, Shipley MT. 1998. Glutamate and synaptic plasticity at mammalian primary olfactory synapses. Ann N Y Acad Sci 855: 457-466.

Gire DH, Schoppa NE. 2008. Long-term enhancement of synchronized oscillations by adrenergic receptor activation in the olfactory bulb. J Neurophysiol 99: 2021-2025.

Griff ER, Mafhouz M, Perrut A, Chaput MA. 2008. Comparison of identified mitral and tufted cells in freely breathing rats: I. Conduction velocity and spontaneous activity. Chem Senses 33: 779-792.

Guthrie KM, Anderson AJ, Leon M, Gall C. 1993. Odor-induced increases in c-fos mRNA expression reveal an anatomical "unit" for odor processing in olfactory bulb. Proc Natl Acad Sci 90: 3329-3333.

Harley CW. 1987. A role for norepinephrine in arousal, emotion and learning?: Limbic modulation by norepinephrine and the Kety hypothesis. Prog Neuropsychopharmacol Biol Psychiatry 11: 419-458.

Harley CW, Darby-King A, McCann J, McLean J. 2006. $\beta 1$-Adrenoceptor or $\alpha 1$-adrenoceptor activation initiates early odor preference learning in rat pups: Support for two mitral cell/cAMP model for odor preference learning. Learn Mem 13: 8-13.

Hayar A, Heyward PM, Heinbockel T, Shipley MT, Ennis M. 2001. Direct excitation of mitral cells via activation of $\alpha 1$-noradrenergic receptors in rat olfactory bulb slices. J Neurophysiol 86: 2173-2182.

Hayar A, Karnup S, Ennis M, Shipley MT. 2004. External tufted cells: A major excitatory element that coordinates glomerular activity. J Neurosci 24: 6676-6685.

Jahr CE, Nicoll RA. 1982. Noradrenergic modulation of dendrodendritic inhibition in the olfactory bulb. Nature 297: 227-229.

Johnson BA, Woo CC, Duong H, Nguyen V, Leon M. 1995. A learned odor evokes an enhanced Fos-like glomerular response in the olfactory bulb of young rats. Brain Res 699: 192-200.

Jones SV, Choi DC, Davis M, Ressler KJ. 2008. Learning-dependent structural plasticity in the adult olfactory pathway. J Neurosci $\mathbf{2 8}$ : 13106-13111.

Karnup SV, Hayar A, Shipley MT, Kurnikova MG. 2006. Spontaneous field potentials in the glomeruli of the olfactory bulb: The leading role of juxtaglomerular cells. Neuroscience 142: 203-221.

Kepecs A, Uchida N, Mainen ZF. 2006. The sniff as a unit of olfactory processing. Chem Senses 31: 167-179.

Langdon PE, Harley CW, McLean JH. 1997. Increased $\beta$-adrenoceptor activation overcomes conditioned olfactory learning deficits induced by serotonin depletion. Brain Res Dev Brain Res 102: 291293.

Malenka RC. 1994. Synaptic plasticity in the hippocampus: LTP and LTD. Cell 78: 535-538.

McLean JH, Harley CW. 2004. Olfactory learning in the rat pup: A model that may permit visualization of a mammalian memory trace. Neuroreport 15: 1691-1697.

McLean JH, Shipley MT. 1991. Postnatal development of the noradrenergic projection from locus coeruleus to the olfactory bulb in the rat. J Comp Neurol 304: 467-477.

McLean JH, Shipley MT, Nickell WT, Aston-Jones G, Reyher CK. 1989. Chemoanatomical organization of the noradrenergic input from locus coeruleus to the olfactory bulb of the adult rat. J Comp Neurol 285: 339349 . 
McLean JH, Harley CW, Darby-King A, Yuan Q. 1999. pCREB in the neonate rat olfactory bulb is selectively and transiently increased by odor preference-conditioned training. Learn Mem 6: 608-618.

Mori K. 1987. Membrane and synaptic properties of identified neurons in the olfactory bulb. Prog Neurobiol 29: 275-320.

Murphy GJ, Glickfeld LL, Balsen Z, Isaacson JS. 2004. Sensory neuron signaling to the brain: Properties of transmitter release from $\mathrm{ON}$ terminals. J Neurosci 24: 3023-3030.

Murphy GJ, Darcy DP, Isaacson JS. 2005. Intraglomerular inhibition: Signaling mechanisms of an olfactory microcircuit. Nat Neurosci 8: 354-364.

Mutoh H, Yuan Q, Knopfel T. 2005. Long-term depression at ON synapses. J Neurosci 25: 4252-4259.

Palmer AM, DeKosky ST. 1993. Monoamine neurons in aging and Alzheimer's disease. J Neural Transm Gen Sect 91: 135-159.

Shipley MT, McLean JH, Zimmer LA, Ennis M. 1996. The olfactory system. In Handbook of chemical neuroanatomy (eds. LW Swanson et al.), pp. 467571. Elsevier, Amsterdam, The Netherlands.

Shao Z, Puche AC, Kiyokage E, Szabo G, Shipley MT. 2009. Two GABAergic intraglomerular circuits differentially regulate tonic and phasic presynaptic inhibition of olfactory nerve terminals. J. Neurophysiol 101: 1988-2001.

Sullivan RM, Leon M. 1987. One-trial olfactory learning enhances olfactory bulb responses to an appetitive conditioned odor in 7-day-old rats. Brain Res 432: 307-311.

Sullivan RM, Wilson DA, Kim MH, Leon M. 1988. Behavioral and neural correlates of postnatal olfactory conditioning: I. Effect of respiration on conditioned neural responses. Physiol Behav 44: 85-90.

Sullivan RM, Wilson DA, Leon M. 1989. Norepinephrine and learninginduced plasticity in infant rat olfactory system. J Neurosci 9: 39984006.

Sullivan RM, McGaugh JL, Leon M. 1991. Norepinephrine-induced plasticity and one-trial olfactory learning in neonatal rats. Brain Res Dev Brain Res 60: 219-228.

Sullivan RM, Zyzak DR, Skierkowski P, Wilson DA. 1992. The role of olfactory bulb norepinephrine in early olfactory learning. Brain Res Dev Brain Res 70: $279-282$.

Sullivan RM, Stackenwalt G, Nasr F, Lemon C, Wilson DA. 2000. Association of an odor with activation of olfactory bulb noradrenergic $\beta$-receptors or locus coeruleus stimulation is sufficient to produce learned approach responses to that odor in neonatal rats. Behav Neurosci 114: 957-962.

Trombley PQ. 1992. Norepinephrine inhibits calcium currents and EPSPs via a G-protein-coupled mechanism in olfactory bulb neurons. J Neurosci 12: 3992-3998.

Trombley PQ. 1994. Noradrenergic modulation of synaptic transmission between olfactory bulb neurons in culture: Implications to olfactory learning. Brain Res Bull 35: 473-484.

Trombley PQ, Shepherd GM. 1992. Noradrenergic inhibition of synaptic transmission between mitral and granule cells in mammalian olfactory bulb cultures. J Neurosci 12: 3985-3991.
Tyler WJ, Petzold GC, Pal SK, Murthy VN. 2007. Experience-dependent modification of primary sensory synapses in the mammalian olfactory bulb. J Neurosci 27: 9427-9438.

Weinshenker D. 2008. Functional consequences of locus coeruleus degeneration in Alzheimer's disease. Curr Alzheimer Res 5: 342-345.

Wilson DA, Leon M. 1988. Spatial patterns of olfactory bulb single-unit responses to learned olfactory cues in young rats. J Neurophysiol 59: $1770-1782$.

Wilson DA, Sullivan RM. 1991. Olfactory associative conditioning in infant rats with brain stimulation as reward: II. Norepinephrine mediates a specific component of the bulb response to reward. Behav Neurosci 105: $843-849$.

Wilson DA, Sullivan RM. 1994. Neurobiology of associative learning in the neonate: Early olfactory learning. Behav Neural Biol 61: 1-18.

Wilson DA, Sullivan RM, Leon M. 1985. Odor familiarity alters mitral cell response in the olfactory bulb of neonatal rats. Brain Res 354: 314-317.

Wilson DA, Sullivan RM, Leon M. 1987. Single-unit analysis of postnatal olfactory learning: Modified olfactory bulb output response patterns to learned attractive odors. J Neurosci 7: 3154-3162.

Wilson DA, Pham TC, Sullivan RM. 1994. Norepinephrine and posttraining memory consolidation in neonatal rats. Behav Neurosci 108: 10531058.

Woo CC, Leon M. 1991. Increase in a focal population of juxtaglomerular cells in the olfactory bulb associated with early learning. J Comp Neurol 305: $49-56$.

Woo CC, Leon M. 1995. Distribution and development of $\beta$-adrenergic receptors in the rat olfactory bulb. J Comp Neurol 352: 1-10.

Woo CC, Coopersmith R, Leon M. 1987. Localized changes in olfactory bulb morphology associated with early olfactory learning. J Comp Neurol 263: $113-125$.

Yuan Q, Harley CW, Bruce JC, Darby-King A, McLean JH. 2000. Isoproterenol increases CREB phosphorylation and ON-evoked potentials in normal and 5-HT-depleted olfactory bulbs in rat pups only at doses that produce odor preference learning. Learn Mem 7: 413421.

Yuan Q, Harley CW, McLean JH, Knopfel T. 2002. Optical imaging of odor preference memory in the rat olfactory bulb. J Neurophysiol 87: 31563159.

Yuan Q, Harley CW, Darby-King A, Neve RL, McLean JH. 2003a. Early odor preference learning in the rat: Bidirectional effects of cAMP response element-binding protein (CREB) and mutant CREB support a causal role for phosphorylated CREB. J Neurosci 23: 4760-4765.

Yuan Q, Harley CW, McLean JH. 2003b. Mitral cell $\beta_{1}$ and 5- $\mathrm{HT}_{2 \mathrm{~A}}$ receptor colocalization and cAMP coregulation: A new model of norepinephrineinduced learning in the olfactory bulb. Learn Mem 10: 5-15.

Received July 30, 2009; accepted in revised form August 26, 2009. 


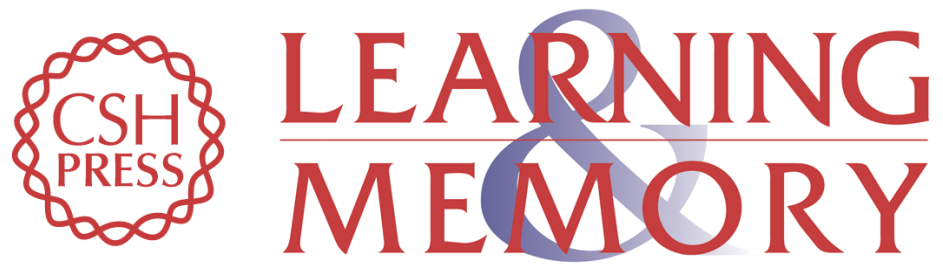

\section{Theta bursts in the olfactory nerve paired with $\beta$-adrenoceptor activation induce calcium elevation in mitral cells: A mechanism for odor preference learning in the neonate rat}

Qi Yuan

Learn. Mem. 2009, 16:

Access the most recent version at doi:10.1101/lm.1569309

References This article cites 61 articles, 19 of which can be accessed free at: http://learnmem.cshlp.org/content/16/11/676.full.html\#ref-list-1

License

Email Alerting

Receive free email alerts when new articles cite this article - sign up in the box at the Service top right corner of the article or click here. 